\title{
Drawing and Surface: Freehand Architectural Drawing Mediated by Digital
}

\author{
Simone Helena Tanoue Vizioli, Joubert José Lancha and Paulo César Castral \\ IAU-USP \\ Avenida Trabalhador São-Carlense 400 - Centro \\ 13566-590 - São Carlos - SP - Brasil \\ simonehtv@sc.usp.br, lanchaj@sc.usp.br, pcastral@sc.usp.br
}

\begin{abstract}
This paper discusses the redefinition of the function of freehand drawing in the design process in view of intuitive digital media. It sets forth an interpretive analysis of an experiment with drawing on opaque tablets, carried out with a group of students of the Instituto de Arquitetura e Urbanismo da Universidade de São Paulo. After a brief review of the current debate on freehand drawing and the advent of digital media, we examine the experiment as a possible way to elicit facts that may contribute to the discussion. To this end, our research has concentrated on the intuitive use enabled by existing digital media. It is our intention that this empirical approximation becomes a pilot experiment for the use of digital tablets in the process of constructing the gaze of the student in Architecture and Urbanism as a reflection on the different cognitive dimensions that constitute the practice of drawing and its reinterpretation to develop new ideas.
\end{abstract}

Freehand drawing. Sketches. Tablets. Design process.

\section{INTRODUCTION}

This paper discusses the redefinition of the function of freehand drawing in the architectural design process, using as a parameter the mediation provided by digital media, especially by intuitive interfaces for graphic data entry, such as the tablet.

We live at a time characterized by abundant visual communication media and by the entertainment industry, the fruit of technological progress. These ingredients define a horizon guided by image, which glorifies the spectacular and the ephemeral. Over the past years, the role of graphic representations has been questioned; in this context, Otxotorena proposes more than a new theorization, but an understanding of the new design processes. At first, he points out the contrast between Jean Prouvé's drawings, made with chalk on blackboard, and the infography Toyo Ito employed in the project of the Serpentine Gallery Pavilion. This contrast, characterized by a relationship between, on the one hand, a humanising filter, which carries in itself a historical and social insertion, and on the other hand, a virtual abstraction oriented by atemporal criteria.(Otxotorena 2007)

For this author, however, it is necessary to review the opinion that pencil drawing has been losing ground to the operation processes mediated by speed and consumerism. The clearly defined roles at the first stage of this process, in which conception was the territory of paper and pencil and project presentation and detailing belonged to digital systems, are now facing dissolution of their limits. The current co-presence of infography, or renders, and traditional drawing in all phases of the design process may be forcing us to deepen the discussion about this historical moment of flexion in the role of representation media in the formation of architectural thinking.

Consequently, we perceive that the discussion about and appreciation of the inherent qualities of freehand drawing are being resumed in the processes of design ideation, both in the field of architecture and design. After some euphoria in the use of digital drawing software, the debate begins to distinguish the function of what is specific to each drawing genre and to emphasise the return to freehand drawing at the initial phases of a project development. Stones \& Cassidy (2010) point out that rudimentary sketches celebrate ambiguity, while computer lines, in standard configurations, seem unmistakable.

This paper intends to encourage this discussion, carrying out a brief review of the topic and presenting and analysing an experiment conducted with students who works in the Research Group ELAC (Estudos de Linguagem em Arquitetura e Cidade) of the Instituto de Arquitetura e Urbanismo da Universidade de São Paulo. 


\section{THE DRAWING AS A THEORETICAL FIELD}

Based on definite ideas, each people, each visual culture at each different time has created its own way to transpose the visible world onto a flat surface. The Egyptians used the perspective in plan; Hindus, radiating perspective; the Chinese and the Japanese, bird's eye perspective; and the Byzantine, inverted perspective (Flores 2003). Classical writers, such as Pliny, reported that the representation of the natural world in drawing was already recognized as an activity both in Greece and Rome (Tavares 2009). At that time, drawing was done on clay tablets - painted or waxed -, papyrus, parchment, and stone. There are also vestiges of drawings on wooden tablets, but with the characteristics of sketches, since this hard material was not suitable for the record of thinner and more precise tracing. A telling example is the well-known Forma Urbis Romae, a massive marble plan that depicted all main buildings of Rome at the time of Septimius Severus.

From history and from architectural drawing come two encyclopaedic works, which join the knowledge about the construction of structures and machines and about the nature: Vitruvius' Treatise (probably written after 27 B.C.) and the manuscript by Villard de Honnecourt, from Picardy, in France (written 1,250 years later). In his Ten Books on Architecture, Vitruvius states that the command of the technique is a condition for an architect's education. His text is the first written reference about the way of representing a building on a surface, using a geometric projection system. Some of the drawings in Villard de Honnecourt's portfolio, from the beginning of the thirteenth century, are considered the starting point for the architectural drawing conventions. As Ackerman (2003) analyses, Honnecourt brings in a single drawing the elevation and the cross-section view of an arch in the choir of Reims cathedral, which, separated only by a vertical line, maintain a correspondence between them. This drawing contains a type of representation that, later, will be largely employed by Italian Renaissance artists.

Throughout history, drawing has always played an important role in the record of facts and objects and in the construction of great works. However, the age of the effective consolidation of a theory about graphic representation is the Renaissance, and two figures can be distinguished as fundamental in this discussion. On the one hand, Brunelleschi, who developed the linear perspective: a system of spatial representation that encompassed the knowledge about mathematics, geometry and anatomy, among other sciences, and on the other hand, Leon Battista Alberti, with his De re aedificatoria, of 1485. For Alberti, drawing was the whole of operations carried out by the human brain, as intention, even before a set of lines is drawn on paper. In architecture, Alberti valued the use of the floor plan to the detriment of illusory representations, such as the perspective, which he considered ideal for painters. The ideal in architecture were these three elements: the floor plan, the cross-section view, and the threedimensional model, with which all metric and composition relations of a work can be expressed. Other seminal figure in consolidating the debate on representation in architecture is Raffaello Sanzio, to whom perspective might also convey incorrect information.

Within this historical framework, we can see that, from this initial period of theoretical production, drawing has developed into alternatives still in use today. Alternatives between rigour and immediacy. In the case of architecture, between a specific tradition - that of the technical drawing - and another one, which bears a more direct relationship with the idea of architecture, connected to the first sketches, or croquis.

\section{THE FREEHAND DRAWING AND THE DESIGN PROCESS}

Drawing as a means of representation is never indifferent, passive or objective; it is an active part of the architect's intention. In the dialogue between architects and their projects the conversation occurs through drawing, a relationship that Gregotti defines as "the only remaining corporeal relationship that the architect has with the physicality of the matter he must form: it is his last 'manuality', and he must defend it obstinately." (Gregotti 2010).

What are the relations between the domain of drawing and the capacity of communication and dialogue of plastic, spatial, and constructive intentions? For Rozestraten (2006), the drawing breaks the inertia of the gaze, articulates thinking associating mental images to visual images.

The freehand drawings produced during the design process are a sum of experiments, perceptions, and impressions. The synthesis process, typical of the development of a design proposal, is characterized as the time to identify unpredictable relations motivated not only by the analysis of a problem's objective data, but also by the repertoire of different understandings resulting from the experiences of those who design. The sketches, in their rapid gestures, are able to catch thinking before it is depurated, that is, the idea flows from mind to paper, concretises itself, rests on the plan and, then, starts to be read, analysed, and modified. Suwa (1997) describes this cycle as 
sketch-inspect-revise, as if it was a conversation of the designers with their own selves.

For Arnheim (1995), sketches are tangible visual percepts that transformed into new mental images, feedback and bring about new formal arguments, which on their turn restructure continually necessarily diffuse images.

Goldschmidt (1991) supposes that it is the very act of sketching that will give access to the several figurative or conceptual mental images that will potentially result in alternatives for the design problem in question. The author argues that the visual design thinking is a mode of reasoning with its own logic, which is as rational as that which could be described in the context of a conventional discursive reasoning.

The design process includes ideation, invention, and expression itself. In this sense, Gregotti (2010) considers vital the exercise of invention, since it goes from perception and memory towards something that does not exist yet; a continuous search for a new and different order, the institution of a new possibility, a new experience of the world materially activated. For him, there is no reason to think that invention, as an inexhaustible social good, cannot be nurtured or taught, and above all transformed into a discipline.

Mitchell \& McCullough (1991) emphasize that, although eye-hand skills are supposedly less important in computer operations, the human ability to perceive and select information critically become more vital than ever at this moment. Handmade drawing is not only a corporeal ability, and the lines drawn by computer are not only a mechanical gesture either. When marking paper with graphite or, indirectly, tracking a line with an electron beam on the screen of a cathode ray tube, what really matters is to know why that information is being drawn and which qualities will achieve the intended objective more effectively.

Several authors emphasize the role and importance of the ambiguity inherent to drawing, especially in the sketching phase. What is being discussed is the possibility of the indetermination of freehand drawing materializing ideas and concepts, making them clear for those who propose them, and at the same time showing an instability in the solutions found that instigate to experiment with other forms for the same problem.

Throughout history, the use of drawing has been associated to cultural and social transformations in the architectural practice. In this universe of drawing possibilities, Robbins (1994) discusses the existence of many studies on architecture as a social practice, in contradiction with few studies on the role of drawing (of representation) in this practice. What is the role of drawing in the cultural and social production of architecture today?

Consequently, the discussion concerning the role of the graphic exercise in the education of an architect gains relevance, since it is directly related to the very discussion on architecture definitions, especially at a particular time of transition, when several opinions about drawing coexist: on the one hand, a detailed drawing that takes over its role in social demands, and on the other hand, a drawing that takes over a spectacular quality, which go as far as erasing architecture itself; on one side, the euphoric resumption of drawing, and on the other, its erasure by the still-new media of the world of infography. (Uria 2007)

From the cultural and individual perspective, drawing plays the most important, if not the most decisive, role in the creation and development of architectural ideas. Thinking, looking, and drawing, in their various interactions and changes, produce the matrix from which derives the design conception.

\section{THE DRAWING MEDIATED BY DIGITAL TABLETS}

The Digital Revolution, which promotes changes in society and its way of life [11], can be understood as the inclusion of computers and internet in the most basic activities of the human beings, providing change in the mode of producing and developing products, expanding the frontiers of knowledge, and increasing exponentially the capacity for processing and solving complex tasks. Consequently, architecture has followed these changes and has been directly influenced by them (Righi, Celani \& Ruschel 2009).

The architects modified their design processes, carrying out new forms of representation, and their drawings have been improved. From the 1980s on, the digital tools originally developed in the 1960s as aids for the design and CAD software started to be used mainly for technical drawing. Today, computer programmes are starting to be used to help the ideation process, leading to a curriculum restructuring in schools of architecture, with the inclusion of courses to provide the use of digital technology in the ideation process (Righi, Celani \& Ruschel 2009).

It was decades of technological development: the first graphic tablet similar to current devices was the RAND tablet, also known as Grafacon, released in 1964. The digitisers became relatively popular in the mid-1970s and the beginning of the 1980 s, in view of the commercial success of ID 
(Intelligent Digitiser) and BitPad, produced by Summagraphics Corp. These digitisers were used as input devices in many CAD (Computer Aided Design) systems of high capacity, as well as included in PCs and CAD software such as AutoCAD.

In the field of technological innovation, it is crucial to tell apart the context within which the innovations are being analysed. According to Pallasmaa (2011), a computer is considered, in general, a solely beneficial invention, which liberates human fantasy and facilitates efficient design work; however, he expresses his concern with computergenerated images, which tend to reduce the capacity for multi-sensory, simultaneous and synchronic imagination. For Pallasmaa, the computer creates a distance between the maker and the object. In his questioning, the use of tablets can reveal itself as a bridge between the two processes, the digital and the analogical. A tablet serves to what this author mentions as an important point in the making of a design:

\begin{abstract}
"In our imagination, the object is simultaneously held in the hand and inside the head, and the imagined and projected physical image is modelled by our bodies. We are inside and outside of the object at the same time. Creative work calls for a bodily and mental identification, empathy and compassion." (Pallasmaa 2011)
\end{abstract}

Thus, the tablet arises as a means that makes possible a new approach to freehand drawing and to the territory of designing. Although the technology of tablet has been around since the 1960s, touch recognition is an innovation that belongs to the new generation, and it means that the force applied on the screen and the lightness of the stroke can now be differentiated, enabling the retrieval of some of the characteristics of freehand drawing. In spite of being at an early stage, it is possible to perceive a re-semantisation of the drawing process through this medium.

Quantrill (2002), an artist, works with an interactive display, connecting ideation process and digital interpretation. In his work, he uses a softboard, and the result is an interweaving of human and computational processes. The spontaneity of the freehand stroke, reducing the mediation between the ideation process and its resulting materialization, made him examine the technical possibility of capturing this movement digitally as a new form of artistic expression.

Studies such as Bilda \& Demirkan's (2003) approach the work on the effect of the use of different media in the conceptual phase of the design process. This study concluded that the traditional (analogical) method had advantages over the digital medium with regard to perception, spatial vision, organizational relation, and solutions proposed. The authors consider that the result may have been influenced by little practical experience in the use of the digital medium.

Several studies and experiments have been conducted in the field of analogical drawing associated with the digital. As examples, we can mention Elliott \& Hearst (2002), Righi (2009), and Righi, Celani \& Ruschel (2009), who analysed how technology interferes in the design process. The experiments were carried out to test the designers' interface with different digital design media, among them standard desktop computers, LCD tablets, and digital desks. Amidst the results obtained, they observed significant differences in productivity and relevant gains in the manipulation and discussion of drawings with the use of devices that include manipulation and manual stroke, such as tablets, digital desks and softboards.

Nardelli (2010) agrees with Laseau (2001) about the possibilities of the use of computers in the teaching of design through an experiment in which the ideation process corresponds to a cycle that goes from the abstract idea to its representation. Representation, on its turn, is considered as an element to feed back the original idea, so that the more this cycle is repeated the more refined the development of the original idea will be.

Therefore, this scenario allows for the constitution of a field of studies relevant to both understanding the cognitive processes typical of the design activity and feeding new digital systems for the design process.

\section{THE DESIGN PROCESS EXPERIMENT}

In face of this moment of transition created by the already explained determinants and in view of the importance of handmade drawing, this research adopted as a method the development of a pilot experiment to produce a comparative and interpretive analysis of drawings made on opaque tablets by a group of students in Architecture and Urbanism at the Institute where the research is being conducted. The activity was underlined by a design exercise that emphasizes the series of decisions that characterize the sketching phase of a design process. Six students from the Study Group on Representation and Language of this Institute took part in the experiment.

The design process experiment was based on the concept of "reinterpretation" (Stones \& Cassidy $2010)$. It is a bi-directional cognitive process of ongoing selection, reflection, and change. Reinterpretation, a continuous action during the ideation phase, generates new and unexpected 
ideas, requiring a perceptive action that goes beyond the externalisation of an idea. Therefore, this was a key element during the ideation exercises. In this activity, the students were asked to design a lamp. There was no restriction regarding either the material to be used in the object or a protocol to develop it. To focus the activity on the ideation process, the researchers defined a condition that students must adopt a freechoice visual reference as motivation for the project, and that they should always maintain a relationship with this reference to favour, but not restrict, an investigative process through drawing.

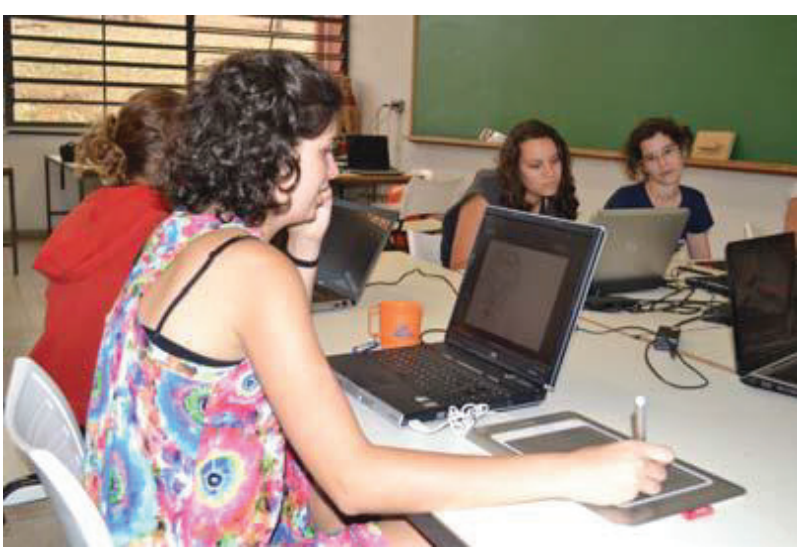

Figure 1: Students from the Architecture program developing the design activity on a digital medium. Source: personal collection, 2011

We opted for not conducting the experiment in a single session, as it had occurred in most of the cases studied, but for allowing students to go back to the project as many times as they thought it was necessary over a 30-day period. During this period, collective work sessions were hold, aiming at solving problems with regard to the use of the software and the tablet, and at checking students' decision making by means of verbal descriptions. We proposed the use of a matrix image editing software, with layers, as the digital working space for the actions carried out on the tablets. Finally, we also adopted screen capture video software to observe the stages of the process.

\section{DISCUSSION}

The parameter to analyse the results was the relationship between the performance achieved in the use of the technical tools (software and tablet) and the design reasoning. At this stage of the research, an attempt was made to favour a more encompassing view so as to catch facts that could contribute new information to the debate.

The results of our research showed a higher degree of diversity in the decision sequence structure than was expected at first. In a group of six students, we identified four different ways of using the technology available for the exercise, divided into two axes, according their characteristics. The following procedures were defined: Juxtaposition (two students); Superposition (two students); Collage (one student); and Arrangement (one student). It was considered that Juxtaposition-Superposition configures one of the axes and CollageArrangement, the other one.

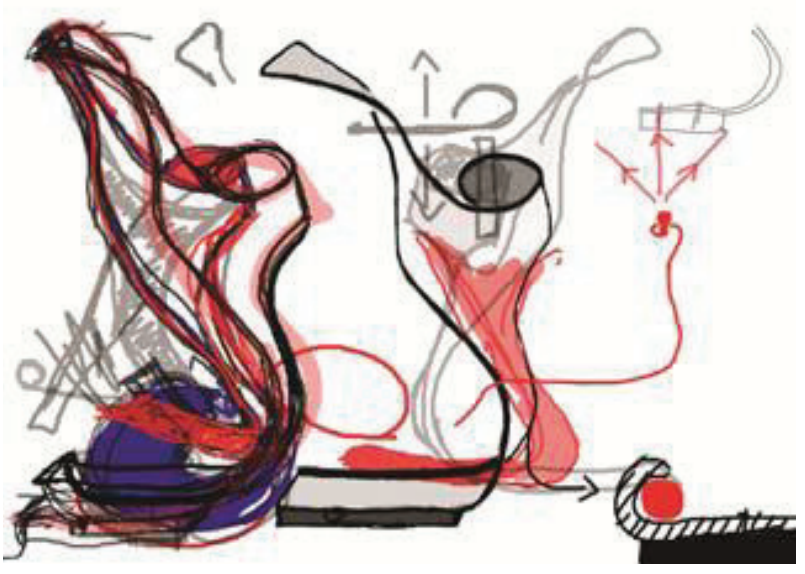

Figure 2: Examples of the processes analysed (Left: Juxtaposition; Right: Superposition). Source: personal collection, 2011

Juxtaposition and Superposition define the axis where the knowledge of the digital medium appears more clearly. In Juxtaposition, the procedure can be characterized as a series of drawings made on opaque paper, that is, the surface is considered opaque and the drawing is distributed over the surface juxtaposing the ideas. On the contrary, in Superposition, there is an intense use of the drawing tool in several superposed layers. This resource is used as an instrument for redrawing, for "reinterpretation", in which each trace is built after revising the previous trace, superposing ideas. This process allowed the student to preserve a memory of the decision sequence, so that it was possible to go back to previous stages, redefining the investigation at the same time as allowing for a comparison between the several products derived from this back and forth movement.

It was observed that the digital medium adopted in the experiment allowed for both a concession to maintain a way of design thinking, typical of the traditional means of drawing, and the creative exploration of a new resource, typical of the digital media. In both cases, the quality of the solutions to the exercise proposed to the students was not significantly lowered. 


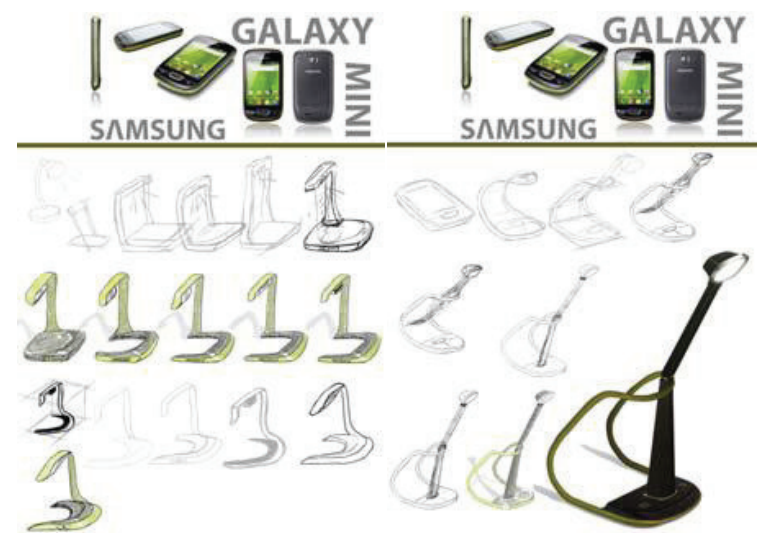

Figure 3: Examples of the processes analysed (Left: Collage; Right: Arrangement). Source: personal collection, 2011

Collage and Arrangement appear as opposed procedures on the same axis, since they reveal the way the students organized their process of "reinterpretation" in relation to their visual references. In the former, Collage, there is a profusion of visual references, the use of brush resources and vector drawing, which unfold in layers indefinitely. It can be perceived an action that, at every moment, brings a new element, which is inserted in an associative chain. The process is configured in the very act of designing. In the latter, Arrangement, it was possible to see a plan to occupy the work surface, divided into a space for the visual reference and other for evenly distributed drawings. In this case, the decision sequences were established beforehand, and the act of designing typical of this phase of the development obeys a clear and defined methodology.

In both cases, it was perceived that the manipulation of different types of data, enabled by the software the students used, was not a language limit to the procedures adopted in the exercise. The degree of indetermination of this resource favoured the creative use of the medium, revealing each student's own characteristic.

In all cases, considering the two axes, it was possible to perceive a general procedure that may be characterized by the concept of reinterpretation. The diversity of the results indicates the possibility of revealing special features in each process. Therefore, it is understood that the technical medium and the procedure, more than defining a limited universe, provide the record of individual characteristics and their subsequent revision.

\footnotetext{
"In its way of representing and structuring action and power, societal and cultural order, interaction and separation, identity and memory, architecture is engaged with fundamental existential questions. All experience implies acts of recollecting, remembering and comparing [...] In memorable experiences of architecture,
}

space, matter and time fuse into one singular dimension, into the basic substance of being, that penetrates our consciousness". (Pallasmaa 2011)

In this sense, on allowing the design process to focus on "reinterpretation", we inhibited the use of the "ready-made forms" provided by most software packages. There is a difference between designing using the computer itself, on which the presence of commands is more imperative, and designing using software functions, "software fluency" (Stones \& Cassidy 2010), in which the action of creating is more visible. Thus, the central axis shifts from the technical knowledge of technology information to an intuitive use that reveals the creative agents' options and positions concerning their historical and cultural context. Designing stops being a merely technical action to regain its function in the construction of a gaze at the world.

\section{CONCLUSION}

We live in a time of reflection and flection, of changes, in which the ideation process that lays the foundation of architecture can be revised by a critical view of the conditions that structure the intellectual and creative work of designers. After a phase of enthusiasm or rejection for digital media, the current stage of technological development allows for considering positions that include several media, without excluding any of them. In this territory, it is possible to focus on the study of the structural relations of the cognitive processes involved in the several phases of the design process, and not solely on a specific medium. Now we can resume the debate about the act of designing as a historical, social, cultural action, among other approaches.

This research was based on the perception that there is an increasing investment in intuitive and kinaesthetic interfaces, which in this study are represented by digital tablets. Such peripherals do not inaugurate a novel logic for digital media, and even less so are limited to the reproduction of the traditional media. Based on the results of the experiment proposed to the students, we perceived the constitution of a hybrid territory: a field of investigation where the several logics and ways of thinking communicate and enable expansion in both bases; a process of resignifying both the use and the products of the media available so far.

Freehand drawing, the subject of this study, can therefore be seen without the recurrent nostalgia of the times before the advent of personal computers. According to this analysis, this type of drawing preserves its fundamental characteristics, such as imprecision and proximity to the designer's thinking, and at the same time borrows cognitive 
resources pertaining to the digital media. In this sense, the act of drawing means the very education of the gaze. Associated with the personality imprinted on the ambiguity of the trace drawn, this gaze can continue to play its fundamental role in the architect's design process through a tablet.

It is our intention that this empirical approximation becomes a pilot experiment for the use of digital tablets in the process of constructing the gaze of the student in Architecture and Urbanism as a reflection on the different cognitive dimensions that constitute the practice of drawing and its reinterpretation to develop new ideas.

\section{ACKNOWLEDGEMENTS}

Instituto de Arquitetura e Urbanismo da USP and FAPESP - Fundação de Amparo à Pesquisa do Estado de São Paulo.

\section{REFERENCES}

Ackerman, J. S. (2003) Architettura e disegno: la rappresentazione da Vitruvio a Gery. Electa, Milano.

Arnheim, R. (1995) Sketching and the Psychology of Design. In Margolin, M. \& Buchanan, R. eds., The Idea of Design, MIT Press, Cambridge.

Bilda, Z., and Demirkan, H. (2003) An insight on designers' sketching activities in traditional versus digital media. Design Studies, 24(1), 27-50.

Elliott, A., and Hearst, M. A. (2002) A Comparison of the Affordances of a Digital Desk and Tablet for Architectural Image Tasks. International Journal of Human-Computer Studies, 56 (2), 173-197.

Flores, C. R. (2003) A problemática do desenho em perspectiva: uma questão de convenção. Zetetiké, 11(19), 81-99.

Goldschmidt, G. (1991) The Dialectics of Sketching, Creativity Research Journal, 4(2), 123143.

Gregotti, V. (2010) Território da Arquitetura (Translated by Berta Waldman e Joan Villa). Perspectiva, Coleção Debates, São Paulo.

Laseau, P. (2001) Graphic thinking for architects \& designers. John Wiley \& Sons, NY, EUA.

Mitchell, W. J., and McCullough, M. (1991) Digital Design Media. Van Nostrand Reinhold, New York.
Nardelli, E. S. (2000) Uso do Computador como Ferramenta de Ensino de Projeto de Arquitetura, Anais do Sigradi 2000. Rio de Janeiro http://cumincades.scix.net/data/works/att/8ff7.conte nt.pdf (10-08-2010).

Otxotorena, J. M. (2007) Dibujo y proyecto en el panorama de la arquitectura contemporánea: impacto y influjo de los nuevos procedimientos gráficos. Revista EGA - expresión gráfica arquitectónica, 12, 60-73.

Pallasmaa, J. (2011) Os olhos da pele: a arquitetura e os sentidos. (Translated by Alexandre Salvaterr) Bookman, Porto Alegre,

Quantrill, M. (2002) Drawing as a Gateway to Computer-Human Integration. Leonardo, 35(1), 73-78.

Righi, T. A. F., Celani, G,. and Ruschel, R.C. (2009) Displays interativos no atelier de projeto: um experimento pedagógico. Anais do Sigradi 2009, 393-395.

Righi, T. A. F. (2009) Displays Interativos como ferramentas de comunicação no processo de projeto de arquitetura. Master's thesis, Universidade Estadual de Campinas, Faculdade de Engenharia Civil, Arquitetura e Urbanismo. Campinas.

Robbins, E. (1994) Why architects draw. The MIT Press, London.

Rozestraten, A. S. (2006) O desenho, a modelagem e o diálogo. Arquitextos-Vitruvius, 07.078 .

http://www. vitruvius.com.br/revistas/read/arquitexto s/07.078/299. (01/2012)

Stones, C., and Cassidy, T. (2010) Seeing and discovering: how do student designers reinterpret sketches and digital marks during graphic design ideation?. Design Studies, 31(5), 439-460.

Suwa, M., and Tversky, B. (1997) What do Architects and Students Perceive in Their Design Sketches?. Design Studies, 18(4), 385-403.

Tavares, P. (2009) O desenho como ferramenta universal: o contributo do processo do desenho na metodologia projectual. Polytechnical Studies Review, VII (12), 7-24.

Uria, L. (2007) Expansión y crisis del dibujo: reflexiones sin imágenes. Revista EGA - expresión gráfica arquitectónica, 12, 50-59. 